\title{
Sustentabilidade Financeira e Orçamental em Contexto de Crise Global Numa Europa de Moeda Única $^{1}$
}

\author{
Financial and Fiscal Sustainability in Context With Global Crisis in an Europe \\ With a Single Currency
}

\author{
João Ricardo Catarino \\ Universidade Técnica de Lisboa, Lisboa - Lisboa, Portugal \\ Jaime Fonseca
}

Universidade Técnica de Lisboa, Lisboa - Lisboa, Portugal

Resumo: Num contexto de crise global, o mercado financeiro internacional deixou de acreditar na capacidade de os países da União Europeia (EU27) fazerem face às dívidas públicas acumuladas e aos encargos financeiros delas resultantes. Como consequência alguns países europeus já solicitaram ajuda financeira às instituições internacionais (Grécia, Irlanda, Portugal e Espanha). Esta investigação visa atestar das obrigações financeiras assumidas pelos Estados-Membros da União Europeia no âmbito do projeto europeu quanto à consolidação das suas finanças públicas. Visa ainda atestar das causas e das debilidades financeiras e orçamentais que, quanto à zona euro, tornaram alguns dos Estados-Membros tão vulneráveis à crise financeira global. Ela visa, finalmente, atestar a trajetória seguida pelos Estados da zona euro e explicar por que falharam os mecanismos de disciplina financeira que deveriam suportar o funcionamento da moeda única.

Palavras-chave: Endividamento. Dívida Pública. Consolidação Orçamental. Contas Públicas.
Abstract: In a context of global crisis, the international financial markets lost faith in the ability of the countries of the European Union (EU27) cope with the accumulated public debts and the financial burden arising. As a result some European countries have requested financial assistance to international institutions (Greece, Ireland, Portugal and Spain). This research aims to certify the financial obligations assumed by the Member of the European Union under the European project as the consolidation of its public finances. It also aims to certify the causes and weaknesses financial and budgetary, as the euro zone, become some of the members vulnerable to the global financial crisis. It aims to, finally, certify the trajectory followed by the euro area Members and explain why the mechanisms of financial discipline failed that should support the functioning of the single euro currency.

Keywords: Public Debt. Public Budget Consolidation. Public Accounts.

1 Recebido em: 06/08/2013

Aprovado em: 22/08/2013 


\section{Problema de Pesquisa e Objetivo da Investigação}

A realidade financeira pública desenrola-se hoje simultaneamente em diferentes espaços ou arenas por uma crescente multiplicidade de agentes. Um desses é o espaço da União Europeia. Esta olha para si mesma como um ator global organizado sob a forma de uma parceria económica e política única entre 27 países europeus que ao longo de cerca de meio século tem garantido a paz, a estabilidade e a prosperidade, ajudando a melhorar os níveis de vida de todos os europeus. Com uma superfície ligeiramente superior a 4 milhões de $\mathrm{km}^{2}$ e com cerca de 495 milhões de habitantes, a União Europeia representa a terceira maior população do mundo, depois da China e da Índia. Ela é, hoje, um mercado único sem fronteiras onde pessoas, mercadorias, serviços e capitais circulam livremente, no contexto de uma moeda única europeia, abrangendo 17 Estados-Membros.

O destacado papel da União Europeia tem-na levado a intervir em vários domínios, desde os Direitos do homem aos transportes e ao comércio, da inovação tecnológica ao reforço da coesão, da agricultura e pescas à cultura e educação, todos eles desdobrados em políticas várias como a monetária ou de concorrência. Daí tem resultado um sucessivo alargamento das políticas comuns e, naturalmente, um reforço dos meios financeiros colocados à disposição dos seus órgãos e instituições através do seu orçamento anual.

Consequentemente, o orçamento da União Europeia eleva-se hoje a cerca de 142 bilhões de euros, um montante impressionante em termos absolutos, mas que representa apenas $1 \%$ da riqueza gerada anualmente pelos Estados-Membros da UE. O essencial destes recursos destina-se a melhorar a vida dos cidadãos e das comunidades da União Europeia, nomeadamente a ajudar as regiões e as populações mais desfavorecidas, bem como a fomentar o emprego e o crescimento em todo o seu território.

A atividade de uma organização desta dimensão afeta muito significativamente a vida dos cidadãos, das empresas e dos Estados que a integram. Seja pela via da execução das políticas comuns, seja através dos 
recursos afetos a fundos estruturais, seja por outros modos, a União está presente nos mais diversos domínios.

Estar-se-á perante um movimento lento de progressivo esbatimento do papel central dos Estados e do reforço das competências centrais da União Europeia no âmbito do processo de construção da ideia europeia. A União Aduaneira, o mercado único europeu, o Ato único Europeu, o Tratado de Maastricht e os critérios de transição para a terceira fase da União Económica e Monetária, o Tratado de Lisboa e, ultimamente, as perspetivas de um acordo sobre o fundo de estabilidade e ou a criação de um fundo europeu de emergência comprovam isso.

Mais recentemente, o PEC - Pacto de Estabilidade e Crescimento pretendeu reforçar a cooperação, a integração das políticas financeiras da União com as dos seus Estados-Membros. Esse pacto revelou-se, todavia, insuficiente para evitar os défices excessivos nos orçamentos nacionais. ${ }^{2}$

Que fatores explicsam isso? Em face de todos os instrumentos legais e políticos tais como atos, pactos e acordos sucessivamente celebrados, como se comportaram os Estados-Membros? Pode-se dizer que eles desenvolveram medidas fiscais e financeiras visando uma clara trajetória de ajustamento rumo à União Económica e Monetária?

Este estudo visa precisamente dar resposta a estas perguntas de partida e, partindo das variáveis abaixo identificadas, obter resultados que demonstrem se ocorreu ou não um progressivo ajustamento estrutural dessas políticas nacionais às necessidades da futura união económica e monetária.

2 Veja-se a Resolução do Conselho Europeu de Amesterdão, de 17 de julho de 1997, o Regulamento (CE) n. 1466/97, do Conselho, de 7 de julho, e Regulamento (CE) n. 1467/97, do Conselho, de 7 de julho, que constituem as bases do PEC - Pacto de Estabilidade e Crescimento.

Veja-se ainda EDUARDO PAZ FERREIRA, União Económica e Monetária - Um Guia de Estudo, e também SOUSA FRANCO, Finanças Europeias, Volume I, edição/ reimpressão, Almedina, 1990; JOSÉ TAVARES, Estudos de Administração e Finanças Públicas, Almedina, 2004 e SOUSA FRANCO, RODOLFO V. LAVRADOR, J. M ALBUQUERQUE CALHEIROS E SÉRGIO GONÇALVES DO CABO, Finanças Europeias: Introdução e Orçamento, Almedina, Coimbra, 1994. 


\section{Objetivo da Pesquisa}

Esta pesquisa visa determinar o comportamento das políticas fiscais e financeiras dos Estados-Membros da União Europeia no período considerado (2000-2011) em ordem a verificar se as políticas por eles desenvolvidas foram de aproximação aos objetivos da União económica e monetária e à moeda única, anteriormente estabelecidos. Com isso pretende-se compreender melhor o fenómeno de crise que assola a Europa dos 27 , descobrindo quais são as suas causas próximas e mais remotas e dar resposta às questões supra formuladas.

\section{Apreciação e Discussão}

\subsection{A União Económica e Monetária e suas Implicações no Comporta- mento dos Estados-Membros}

A substituição das moedas nacionais pelo euro foi formalmente analisada pela primeira vez em 1994 pelo Instituto Monetário Europeu (IME). As atividades preparatórias visando a introdução do euro como moeda única europeia decorreram ao longo de vários anos.

Em $1^{\circ}$ de janeiro de 2002 o euro foi introduzido em 12 países: Alemanha, Áustria, Bélgica, Espanha, Finlândia, França, Grécia, Holanda, Irlanda, Itália, Luxemburgo e Portugal. A Eslovénia adotaria o euro em 2007, seguida do Chipre e Malta (2008), da Eslováquia (2009) e da Estónia (2011). Os 10 Estados-Membros não participantes são: Bulgária, Dinamarca, Hungria, Letónia, Lituânia, Polónia, Reino Unido, República Checa, Roménia e Suécia. Para o efeito foi celebrado em o Pacto de Estabilidade e Crescimento (PEC). Este veio a ser o enquadramento regulamentar para a coordenação das políticas orçamentais nacionais na União Económica e Monetária (UEM). Ele foi estabelecido com o objetivo de salvaguardar a solidez das finanças públicas dos Estados-Membros, considerada indispensável ao bom funcionamento da União Económica e Monetária (UEM) comportando duas vertentes essenciais. 


\subsubsection{O Pacto de Estabilidade e Crescimento (PEC)}

O Pacto de Estabilidade e Crescimento (PEC), de 1997, não é um Pacto Intergovernamental, mas uma resolução política materializada em dois Regulamentos comunitários. Ele insere-se na terceira fase da União Económica e Monetária (UEM), iniciada em $1^{\circ}$ janeiro de 1999. E visou garantir a continuação do esforço de disciplina orçamental, por parte dos Estados-Membros, após a introdução da moeda única. ${ }^{3}$

A médio prazo, os Estados-Membros comprometeram-se a respeitar o objetivo de manter uma situação próxima do equilíbrio orçamental e a atualizar anualmente junto do Conselho e da Comissão o programa de estabilidade apresentado. Paralelamente, os Estados que não participaram na terceira fase da UEM, ou seja, os Estados que não adotaram o euro, tornou-se obrigatório apresentar um programa de convergência.

A União Económica e Monetária (UEM) designa um processo destinado a harmonizar as políticas económicas e monetárias dos Estados-Membros da União, que tinha o objetivo de instaurar uma moeda única, o euro. A UEM foi objeto de uma Conferência Intergovernamental (CIG), realizada em dezembro de 1991, em Maastricht.

A UEM processou-se em três fases:

- 1. ${ }^{\text {a }}$ Fase (de $1^{\circ}$ de julho de 1990 a 31 de dezembro de 1993): consagrando a livre circulação de capitais entre os Estados-Membros, o reforço da coordenação das políticas económicas e intensificação da cooperação entre os bancos centrais.

- $\quad$ 2. $^{\text {a }}$ Fase (de $1^{\circ}$ de janeiro de 1994 a 31 de dezembro de 1998): determinando uma convergência das políticas económicas e

\footnotetext{
3 O Pacto de Estabilidade e Crescimento é composto por uma resolução do Conselho Europeu (adotada em Amesterdão, em 17 de junho de 1997) e dois regulamentos do Conselho que estabelecem as modalidades técnicas da resolução (controlo das situações orçamentais e coordenação das políticas económicas; aplicação do procedimento relativo aos défices excessivos). São eles o Regulamento (CE) n. 1466/97, do Conselho, de 7 de julho, relativo ao esforço de supervisão das situações orçamentais e à supervisão e coordenação das políticas económicas, com as alterações introduzidas pelo Regulamento (CE) n. 1055/2005) e o Regulamento (CE) n. 1467/97, do Conselho, de 7 de julho, que constituem as bases do PEC - Pacto de Estabilidade e Crescimento.
} 
monetárias dos Estados-Membros (com vista a assegurar a estabilidade dos preços e a sanidade das finanças públicas), bem como a criação do Instituto Monetário Europeu (IME) e, posteriormente, do Banco Central Europeu (BCE) em 1998.

- $\quad$ 3. ${ }^{\text {a }}$ Fase (desde $1^{\circ}$ de janeiro de 1999): procedendo à fixação irrevogável das taxas de câmbio e introdução da moeda única nos mercados cambiais e nos pagamentos eletrónicos bem como à introdução do euro fiduciário.

\subsubsection{As Obrigações Decorrentes do PEC}

Os dois maiores desafios para assegurar o êxito a longo prazo da UEM eram:

a) a prossecução da consolidação orçamental;

b) o desenvolvimento de uma coordenação mais estreita das políticas económicas de todos os Estados-Membros. ${ }^{4}$

O PEC (1997) $)^{5}$ obrigou os Estados-Membros da União Económica e Monetária a desenvolver proativamente programas anuais de estabilidade (convergência), através dos quais deveriam desenvolver políticas de aproximação aos objetivos de estabilidade e consolidação das contas públicas tendo em vista alcançar ou manter um quadro orçamental sólido a médio prazo, tendo em conta os vários impactos orçamentais negativos conhecidos ( $v$. g. os défices excessivos, as dívidas públicas acima do limite fixado). Os programas apresentados pelos Estados-Membros deveriam

4 O Pacto de Estabilidade e Crescimento veio abrir a possibilidade ao Conselho de sancionar um Estado-Membro participante que não adote as medidas necessárias para corrigir uma situação de défice excessivo ("procedimento em caso de défice excessivo"). Numa fase inicial, a sanção tomará a forma de depósito sem juros junto da Comunidade, mas poderá ser convertida em coima, se o défice excessivo não for corrigido nos dois anos seguintes. A aplicação das sanções não é, contudo, automática e depende de uma avaliação das circunstâncias pelo Conselho, como é o caso agora, das dificuldades acrescidas resultantes da recente crise financeira e económica dos anos de 2008 e seguintes.

5 Publicado no Jornal Oficial n. C 236 de 02/08/1997 - Resolução do Conselho Europeu sobre o Pacto de Estabilidade e Crescimento, Amesterdão, 17 de junho de 1997, (97/C 236/01). 
ser objeto de avaliação pela Comissão Europeia e submetidos ao parecer do Conselho.

Por outro lado, foram criados, com caráter preventivo dois instrumentos políticos que podem ser utilizados para evitar a ocorrência ou a prolação no tempo de défices excessivos. Assim, no Âmbito destas preocupações o PEC veio a prescrever dois procedimentos específicos:

a) Por um lado o Conselho Europeu, com base numa proposta da Comissão, poderia enviar um alerta precoce ao Estado-Membro em causa para prevenir a ocorrência de um défice excessivo;

b) Por outro, a Comissão passou a poder igualmente apresentar uma primeira recomendação a um Estado-Membro para que respeite as obrigações do Pacto de Estabilidade e Crescimento.

O PEC veio também a disciplinar, com caráter repressivo, o denominado procedimento relativo aos défices excessivos (PDE). Este deve ser desencadeado quando o limite de $3 \%$ do PIB previsto no Tratado é superado. Se for constatado que existe uma situação de défice excessivo na aceção do Tratado, o Conselho Europeu passou a deter o poder de fazer recomendações expressas ao Estado-Membro em causa para que corrija o défice excessivo e dá-lhe um período de tempo para o fazer. Caso o Estado-Membro em causa não siga as recomendações do Conselho, é desencadeada a fase seguinte do processo que, para os Estados-Membros da zona euro, pode culminar na aplicação de sanções. Assim, é possível concluir que a implementação da união económica e monetária representou para os Estados-Membros novos limites em matéria económica, fiscal e financeira tendo precisamente em vista alcançar um elevado grau de consolidação das contas públicas desses Estados-Membros.

\subsection{Sustentabilidade das Finanças Públicas Europeias a Longo Prazo}

As características próprias do modelo social europeu e as especificidades económicas, geográficas, históricas e demográficas dos Estados da União europeia impuseram um modelo de Estado com fortes preocupações sociais e redistributivas da riqueza e do bem-estar. Alguns destes vetores evoluíram em sentido negativo (v. g. o envelhecimento da população, o desemprego, etc.) levando os Estados-Membros a desenvolver po- 
líticas públicas de apoio, com elevados custos financeiros e repercussões muito agravadas nas suas finanças públicas.

Assim, os Estados-Membros da União Europeia foram colocados perante o desafio de garantir a sustentabilidade das suas finanças a longo prazo face ao impacto orçamental iminente desses vetores negativos. Tendo em conta o destaque dado à sustentabilidade a longo prazo das finanças públicas dos Estados da União Europeia, desde logo na reforma de 2005 do próprio Pacto (PEC), foram feitas projeções orçamentais a longo prazo comuns a toda a União Europeia e individuais de cada um Estados-Membros através de um relatório sobre a sustentabilidade das finanças públicas europeias, tendo em vista fornecer indicações económicas precisas sobre as trajetórias que cada Estado deveria seguir tendo em vista desenvolver programas para alcançar a estabilidade e a convergência.

A verdade é que, segundo os resultados que se descreve a seguir, esses Estados, estando embora na posse dessa informação relevante, não encetaram nem prosseguiram programas de ajustamento estrutural visando a consolidação a médio prazo das suas contas públicas.

Em termos formais a Resolução do Conselho Europeu de Amesterdão sobre o Pacto de Estabilidade e Crescimento deu aos Estados-Membros, ao Conselho e à Comissão orientações políticas firmes para executarem devidamente o Pacto de Estabilidade e Crescimento. Ela incentivou os Estados-Membros a realizarem políticas orçamentais sãs na terceira fase da União Económica e Monetária (UEM). Para o efeito foi formalmente reforçada a supervisão e a coordenação das políticas orçamentais materializadas num regulamento europeu. ${ }^{6}$

\footnotetext{
6 Trata-se do Regulamento (CE) n. 1446/97 do Conselho, de 7 de julho de 1997, relativo ao reforço da supervisão das situações orçamentais e à supervisão e coordenação das políticas económicas. Este Regulamento tem por objetivo a supervisão das políticas orçamentais dos Estados-Membros suscitando o desenvolvimento de medidas preventivas destinadas a assegurar a disciplina orçamental visando o bom funcionamento da União Europeia. O regulamento diz respeito tanto aos Estados-Membros que adotaram a moeda única como aos que ainda não participam.
} 
Ainda assim, porém, esse controlo revelou-se insuficiente para inverter a trajetória de endividamento seguida pela maioria dos Estados europeus. Ver-se-á o porquê e como.

\subsection{O Controle Financeiro da União Europeia e os Défices Excessivos}

A União Económica e Monetária (UEM), a moeda única, o Pacto de Estabilidade e Crescimento (PEC), o Tratado de Lisboa e vários outros atos normativos criaram regras fundamentais em matéria financeira, visando resolver o problema dos défices excessivos e reforçar as fontes de financiamento da União Europeia. Não é, ainda, de excluir a criação de um imposto europeu. O sistema de recursos próprios poderá ser reforçado através de um imposto já cobrado nos EMs canalizando-o para o orçamento da União Europeia como um verdadeiro recurso próprio. Isso estabeleceria uma ligação mais direta entre a União e os contribuintes europeus.

O Tratado de Lisboa veio fornecer um quadro institucional renovado instituindo o princípio geral de que a União Europeia possui os meios necessários para atingir os seus objetivos e realizar com êxito as suas políticas e o seu orçamento é integralmente financiado por recursos próprios, sem prejuízo de outras receitas. ${ }^{7}$ Despesas comunitárias exigem receitas comunitárias, todas elas agregadas em torno de um orçamento comum - o orçamento da União Europeia.

O sucesso da política monetária instaurada depois de 1999 dependia do rigor da execução dos orçamentos dos Estados-Membros. Assim, as questões sobre disciplina orçamental ganharam um enorme peso influenciando e sendo influenciada pelo modo como cada Estado-Membro executa a sua própria disciplina orçamental. A política económica da União

7 Ver BENOÎT CHEVAUCHEZ, Les effets de la construction européenne sur notre système de finances publiques, MARIE-CHRISTINE ESCLASSAN, Les effets de la construction européenne sur le pouvoir budgétaire des États membres : le cas de la France, GILBERT ORSONI, Les pratiques de régulation budgétaire, na RFFP, com o tema, L'Union européenne et les finances publiques nationales, e PIERRE LLAU, Les contractions budgétaires en Europe, RFPP - Revue française de finances publiques, n. 68, 1999. 
Europeia, regulada nos artigos $120^{\circ}$ e segs. do Tratado sobre o Funcionamento da União Europeia (TFUE) obriga, em especial no seu artigo $126^{\circ}$ e bem assim no Protocolo 20 relativo ao Procedimento Aplicável em Caso de Défice Excessivo ${ }^{8}$, a uma disciplina orçamental que atende a duas variáveis essenciais: a relação entre o défice orçamental e o PIB e entre a dívida pública e o PIB, a preços de mercado fixados, respetivamente, em:

a) $3 \%$ para a relação entre o défice orçamental programado ou verificado e o produto interno bruto a preços de mercado;

b) $60 \%$ para a relação entre a dívida pública e o produto interno bruto a preços de mercado.

O Regulamento do Conselho n. 3.605/93, de 22 de novembro de 1993, veio definir o défice como a necessidade líquida de financiamento das administrações públicas, tal como decorre do Sistema Europeu de Contas (SEC), e descreve dívida como o valor nominal da dívida bruta consolidada das administrações públicas, no final do ano. Através do PEC:

a) Os Estados-Membros comprometeram-se a agir sobre as suas contas e finanças públicas de modo se aproximarem da situação de equilíbrio ou de excedente e, se necessário, a aplicar as medidas de correção necessárias para resolver ou evitar as situações de défice excessivo.

b) A Comissão e o Conselho ficaram obrigados a acompanhar a situação orçamental dos Estados-Membros, a elaborar relatórios,

\footnotetext{
8 Ver Regulamento (CE) n. 3605/93 do Conselho, de 22 de novembro de 1993, relativo à aplicação do protocolo sobre o procedimento relativo aos défices excessivos anexo ao Tratado que institui a Comunidade Europeia, Jornal Oficial n. L 332 de 31/12/1993 p. 0007 - 0009 e também a Resolução do Conselho Europeu de Amesterdão, de 17 de julho de 1997, o Regulamento (CE) n. 1466/97, do Conselho, de 7 de julho, e o Regulamento (CE) n. 1467/97, do Conselho, de 7 de julho, que constituem as bases do PEC - Pacto de Estabilidade e Crescimento. Algumas críticas oportunas sobre tais limites, nomeadamente sobre o seu carácter aleatório podem ser encontradas em EDUARDO PAZ FERREIRA, Da dívida pública e das Garantias dos Credores do Estado, Almedina, Coimbra, 1995 e JOÃO AMADOR e JORGE CORREIA DA CUNHA, Regras orçamentais na UE: Algumas linhas de orientação para a sua reforma, Boletim Económico do Banco de Portugal, dezembro de 2004, em http://docentes.fe.unl.pt/ jamador/Textos/BE_PEC.pdf.
} 
pareceres e recomendações pelos quais sejam tomadas decisões céleres visando levar os Estados a tomar as medidas necessárias para sair da situação de défice excessivo.

Esta disciplina não foi suficiente para evitar que alguns Estados apresentassem situações de défice e de endividamento excessivo como se pode ver na Tabela 1. As normas e programas comunitários estabeleceram objetivos de médio prazo e trajetórias de ajustamento importantes para que os Estados-Membros pudessem alcançar as metas de excedente ou equilíbrio requeridos para a estabilidade da união económica e monetária. Elas, de facto, monitorizam o cumprimento do défice que consta dos Tratados Europeus (ver o Regulamento (CE) n. 1466/97, do Conselho, de 1997, relativo ao esforço de supervisão das situações orçamentais e à supervisão e coordenação das políticas económicas, com as alterações introduzidas pelo Regulamento (CE) n. 1055/2005). ${ }^{9}$

Nos termos dos artigos $134^{\circ}$ do TFUE e $4^{\circ}$ e $5^{\circ}$ do Regulamento (CE) n. 1.466/97 cabe ao Conselho acompanhar o cumprimento dos programas de estabilidade com base nas informações fornecidas pelos Estados-Membros e nas avaliações da Comissão e do Comité Económico e Financeiro (artigo $134^{\circ}$ do TFUE), examinando:

a) O objetivo orçamental de médio prazo apresentado pelo Estado-Membro.

b) Se as hipóteses de natureza económica em que o programa se baseia são realistas, se a trajetória de ajustamento ao objetivo de médio prazo prevista no programa é adequada e se as medidas tomadas e/ou propostas são suficientes para respeitar essa trajetória de ajustamento a fim de alcançar o objetivo orçamental de médio prazo durante o ciclo.

\footnotetext{
9 O Regulamento (CE) n. 1055/2005 do conselho de 27 de junho de 2005 que altera o Regulamento (CE) n. 1466/97 relativo ao reforço da supervisão das situações orçamentais e à supervisão e coordenação das políticas económicas foi publicado no JO L 174/4 em 7 de julho de 2005. Veja-se também o Anexo II - Melhorar a Aplicação do Pacto de Estabilidade e Crescimento em <http://www.fd.uc.pt/CI/CEE/pm/LegCE/PactoRelatorio_Conselho-23-3-2005.htm>.
} 
Se o Conselho detetar situações de desvio significativo, efetivo ou previsível, da situação orçamental em relação ao objetivo a médio prazo ou em relação à respetiva trajetória de ajustamento, deve lançar um alerta rápido para evitar a ocorrência de um défice excessivo e formular uma recomendação ao Estado-Membro para que esse tome as medidas de ajustamento necessárias ( $\operatorname{artigo} 6^{\circ}$ n. 2 do Regulamento (CE) n. 1466/97.

Existe alguma margem de flexibilidade na delimitação do que se devam considerar défices excessivos uma vez que o TFUE estabelece no seu artigo $162^{\circ}$ n. 2 als. a) e b) que o caráter excessivo do défice não se verifica:

a) Se a relação entre o défice orçamental programado ou verificado e o produto interno bruto excede um dado valor de referência, exceto:

- Se essa relação tiver baixado de forma substancial e contínua e tiver atingido um nível que se aproxime do valor de referência;

- Ou, em alternativa, se o excesso em relação ao valor de referência for meramente excecional e temporário e se aquela relação continuar perto do valor de referência;

b) Se a relação entre a dívida pública e o produto interno bruto exceder um valor de referência, exceto se essa relação se encontrar em diminuição significativa e se estiver a aproximar, de forma satisfatória, do valor de referência.

Esta solução, podendo ser criticável é compreensível se for tomada em consideração a situação de partida de alguns Estados-Membros aderentes à moeda única, em face na natureza claramente estrutural dos défices e desequilíbrios orçamentais.

Nos termos do artigo $126^{\circ}$ n. 6 do TFUE compete ao Conselho Europeu declarar a existência de um défice excessivo:

- Devendo adotar sem demora, sob proposta da Comissão, recomendações que dirige ao Estado-Membro para que este ponha termo a essa situação num dado prazo, as quais, num primeiro momento, não serão tornadas públicas (n. 8 e 9 do artigo $126^{\circ}$ 
do TFUE), podendo sê-lo se o Estado não tomar medidas eficazes no prazo que lhe tiver sido estabelecido;

- Se um Estado-Membro persistir em não pôr em prática as recomendações do Conselho, este pode decidir notificar esse Estado-Membro para, num dado prazo, tomar medidas eficazes destinadas a reduzir o défice para um nível que o Conselho considerar necessário para obviar à situação. Nesse caso, o Conselho pode pedir ao Estado-Membro que lhe apresente relatórios de acordo com um calendário específico, a fim de analisar os esforços de ajustamento desse Estado-Membro;

O n. 4 do Regulamento n. 1467/97, do Conselho, de 7 de julho de $1997,{ }^{10}$ relativo à aceleração e clarificação da aplicação do procedimento relativo aos défices excessivos, estabelece como limiar mínimo uma melhoria anual mínima de $0,5 \%$ do PIB, como valor de referência, do seu saldo corrigido de variações cíclicas, líquido de medidas pontuais ou temporárias, a fim de assegurar a correção da situação de défice excessivo no prazo fixado na recomendação;

- Finalmente, se a situação de défice excessivo persistir o Conselho pode impor e aplicar ao Estado-Membro um conjunto de procedimentos e sanções:

- Exigir que o Estado-Membro em causa divulgue informações complementares, a determinar pelo Conselho, antes de emitir quaisquer obrigações e títulos;

- Convidar o Banco Europeu de Investimento a reconsiderar a sua política de empréstimos em relação ao Estado-Membro em causa;

- Exigir do Estado-Membro a constituição, junto da União Europeia, de um depósito não remunerado de montante apropriado a fixar segundo os critérios previstos no Regulamento (CE) n. 1466/97, até que, na opinião do Conselho, o défice excessivo tenha sido corrigido,

10 O Regulamento n. 1467/97, do Conselho, de 7 de julho de 1997, publicado no Jornal Oficial L n. 209 de 02/08/1997 foi alterado pelo 1056/2005 de 7. 7. 2005 - JO, L, 174/5. 
- A conversão em multa pelo Conselho desse depósito se, dois anos após a data da decisão de impor ao Estado-Membro participante a constituição de um depósito, o Conselho considerar que o défice excessivo não foi corrigido;

- Impor multas de importância apropriada.

Todo este procedimento pode ser objeto de revisão caso ocorram alterações sensíveis da situação do Estado-Membro ou quando se verifique uma conjuntura ou circunstância económica adversa e imprevista que produza um impacto desfavorável significativo nas finanças públicas desse Estado. Nesse caso, o Conselho pode decidir, com base em recomendação da Comissão, alterar as suas exigências, notificando o Estado desses ajustamentos.

A verdade é que todo este quadro normativo e regulatório não impediu a persistência de défices excessivos num bom número de Estado-Membros, conforme se pode ver na Tabela 1.

Tais défices, como se pode ver, agravaram-se com a crise do subprime e com a crise financeira e económica que lhe sobreveio, sendo claramente crescente o número dos Estados em situação de défice excessivo. Com isto em mente, bem se vê que a consolidação orçamental na Europa a 27 e na Europa da zona Euro efetivamente não ocorreu. Foram fatores de ordem externa, como se disse, que concorram para o agravamento dos défices dos Estados europeus. Mas como será que esses Estados desenvolveram as suas políticas orçamentais, financeiras e fiscais do mesmo período? É possível ver os dados que emergem das variáveis escolhidas para a análise. 
Tabela 1: Saldos orçamentais na UE-27, 1999-2011 (Em percentagem do PIB)

\begin{tabular}{|c|c|c|c|c|c|c|c|c|c|c|c|c|c|}
\hline & 1999 & 2000 & 2001 & 2002 & 2003 & 2004 & 2005 & 2006 & 2007 & 2008 & 2009 & 2010 & 2011 \\
\hline UE-27 & -1.0 & 0.6 & -1.5 & -2.6 & -3.2 & -2.9 & -2.4 & -1.5 & -0.9 & -2.4 & -6.9 & -6.5 & -4.5 \\
\hline Zona Euro & -1.5 & -0.1 & -1.9 & -2.6 & -3.1 & -2.9 & -2.5 & -1.3 & -0.7 & -2.1 & -6.4 & -6.2 & -4.1 \\
\hline Alemanha & -1.6 & 1.1 & -3.1 & -3.8 & -4.2 & -3.8 & -3.3 & -1.6 & 0.2 & -0.1 & -3.2 & -4.3 & -1.0 \\
\hline Áustria & -2.3 & -1.7 & 0.0 & -0.7 & -1.5 & -4.4 & -1.7 & -1.5 & -0.9 & -0.9 & -4.1 & -4.5 & -2.6 \\
\hline Bélgica & -0.6 & 0.0 & 0.4 & -0.1 & -0.1 & -0.3 & -2.7 & 0.1 & -0.3 & -1.0 & -5.6 & -3.8 & -3.7 \\
\hline Bulgária & 0.1 & -0.5 & 1.1 & -1.2 & -0.4 & 1.9 & 1.0 & 1.9 & 1.2 & 1.7 & -4.3 & -3.1 & -2.1 \\
\hline Chipre & -4.3 & -2.3 & -2.2 & -4.4 & -6.6 & -4.1 & -2.4 & -1.2 & 3.5 & 0.9 & -6.1 & -5.3 & -6.3 \\
\hline Dinamarca & 1.3 & 2.3 & 1.5 & 0.4 & 0.1 & 2.1 & 5.2 & 5.2 & 4.8 & 3.2 & -2.7 & -2.5 & -1.8 \\
\hline Eslováquia & -7.4 & -12.3 & -6.5 & -8.2 & -2.8 & -2.4 & -2.8 & -3.2 & -1.8 & -2.1 & -8.0 & -7.7 & -4.8 \\
\hline Eslovénia & -3.0 & -3.7 & -4.0 & -2.4 & -2.7 & -2.3 & -1.5 & -1.4 & 0.0 & -1.9 & -6.1 & -6.0 & -6.4 \\
\hline Espanha & -1.2 & -0.9 & -0.5 & -0.2 & -0.3 & -0.1 & 1.3 & 2.4 & 1.9 & -4.5 & -11.2 & -9.3 & -8.5 \\
\hline Estónia & -3.5 & -0.2 & -0.1 & 0.3 & 1.7 & 1.6 & 1.6 & 2.5 & 2.4 & -2.9 & -2.0 & 0.2 & 1.0 \\
\hline Finlândia & 1.7 & 6.9 & 5.1 & 4.1 & 2.6 & 2.5 & 2.8 & 4.1 & 5.3 & 4.3 & -2.5 & -2.5 & -0.5 \\
\hline França & -1.8 & -1.5 & -1.5 & -3.1 & -4.1 & -3.6 & -2.9 & -2.3 & -2.7 & -3.3 & -7.5 & -7.1 & -5.2 \\
\hline Grécia & n.d. & -3.7 & -4.5 & -4.8 & -5.6 & -7.5 & -5.2 & -5.7 & -6.5 & -9.8 & -15.6 & -10.3 & -9.1 \\
\hline Holanda & 0.4 & 2.0 & -0.2 & -2.1 & -3.1 & -1.7 & -0.3 & 0.5 & 0.2 & 0.5 & -5.6 & -5.1 & -4.7 \\
\hline Hungria & -5.5 & -3.0 & -4.1 & -9.0 & -7.3 & -6.5 & -7.9 & -9.3 & -5.1 & -3.7 & -4.6 & -4.2 & 4.3 \\
\hline Irlanda & 2.7 & 4.7 & 0.9 & -0.4 & 0.4 & 1.4 & 1.7 & 2.9 & 0.1 & -7.3 & -14.0 & -31.2 & -13.1 \\
\hline Itália & -1.9 & -0.8 & -3.1 & -3.1 & -3.6 & -3.5 & -4.4 & -3.4 & -1.6 & -2.7 & -5.4 & -4.6 & -3.9 \\
\hline Letónia & -3.9 & -2.8 & -2.0 & -2.3 & -1.6 & -1.0 & -0.4 & -0.5 & -0.4 & -4.2 & -9.8 & -8.2 & -3.5 \\
\hline Lituânia & -2.8 & -3.2 & -3.5 & -1.9 & -1.3 & -1.5 & -0.5 & -0.4 & -1.0 & -3.3 & -9.4 & -7.2 & -5.5 \\
\hline Luxemburgo & 3.4 & 6.0 & 6.1 & 2.1 & 0.5 & -1.1 & 0.0 & 1.4 & 3.7 & 3.0 & -0.8 & -0.9 & -0.6 \\
\hline Malta & -7.7 & -5.8 & -6.4 & -5.8 & -9.2 & -4.7 & -2.9 & -2.8 & -2.4 & -4.6 & -3.8 & -3.7 & -2.7 \\
\hline Polónia & -2.3 & -3.0 & -5.3 & -5.0 & -6.2 & -5.4 & -4.1 & -3.6 & -1.9 & -3.7 & -7.4 & -7.8 & -5.1 \\
\hline Portugal & -3.1 & -3.3 & -4.8 & -3.4 & -3.7 & -4.0 & -6.5 & -4.6 & -3.1 & -3.6 & -10.2 & -9.8 & -4.2 \\
\hline Reino Unido & 0.9 & 3.6 & 0.5 & -2.1 & -3.4 & -3.5 & -3.4 & -2.7 & -2.7 & -5.0 & -11.5 & -10.2 & -8.3 \\
\hline Rep. Checa & -3.6 & -3.6 & -5.6 & -6.5 & -6.7 & -2.8 & -3.2 & -2.4 & -0.7 & -2.2 & -5.8 & -4.8 & -3.1 \\
\hline Roménia & -4.4 & -4.7 & -3.5 & -2.0 & -1.5 & -1.2 & -1.2 & -2.2 & -2.9 & -5.7 & -9.0 & -6.8 & -5.2 \\
\hline Suécia & 0.9 & 3.6 & 1.5 & -1.3 & -1.0 & 0.6 & 2.2 & 2.3 & 3.6 & 2.2 & -0.7 & 0.3 & 0.3 \\
\hline
\end{tabular}

Nota: Todos os países indicados aderiram à Zona Euro em 1999, com exceção da Grécia (2001), Eslovénia (2007), Malta e Chipre (2008), Eslováquia (2009) e Estónia (2011).

Fonte: INE, Eurostat; Cálculos dos autores deste artigo

\section{Metodologia}

Para alcançar os objetivos pretendidos, a opção tomada foi a de recorrer ao estudo de caso múltiplo por ser o mais adequado para os fins em vista (YIN, 2009). Justifica-se esta opção em resultado da necessidade de apreciar um conjunto de variáveis relativamente aos 27 Estados da zona 
euro. O objeto de análise é a política financeira e fiscal aqui estudada a partir de um conjunto de variáveis selecionadas.

\section{Dados}

Os dados resultaram de consulta do Eurostat, referentes aos países da EU27, nas variáveis seguintes:

Os impostos correntes sobre o rendimento, património;

1) Taxa de impostos e contribuições para segurança social sobre os rendimentos do trabalho assalariado a remuneração total dos trabalhadores;

2) Contribuições sociais;

3) Despesa total do Estado;

4) Receita total do Estado.

\section{Métodos}

Tendo em vista dar resposta às questões de pesquisa,procede-se à análise gráfica e analítica, num contexto comparativo, sendo que para esta foram usados os modelos de agrupamento via modelos de classes latentes (FONSECA, 2012; FONSECA; CARDOSO, 2007). Esses modelos foram introduzidos por Lazarsfield e Henry (1968), e, sucessivamente aplicados, entre outros, por McCutcheon (1987) e Clogg (1995), para evidenciar a sua estrutura subjacente.

Os modelos de classes latentes pretendem justificar as associações observadas entre duas ou mais variáveis observadas, usando as relações destas variáveis com uma variável latente subjacente, com duas ou mais classes, conforme Marsden (1985).

Estes modelos estatísticos permitem assim testar se um conjunto de classes não observadas, latentes, justifica convenientemente a associação entre as variáveis observadas. Neste contexto, uma solução específica, constituída por um conjunto de classes latentes, é razoável quando conduz à minimização da associação entre variáveis observadas, dentro de cada classe. Esta minimização conduz ao princípio básico de independência ou independência condicional. 
Assim, postulando uma população heterogénea, constituída por $\mathrm{S}$ grupos ou sub populações homogéneas (classes latentes), o modelo de classes latentes é definido pela variável Y com S categorias ou tipos latentes de alunos, descritos através das variáveis observadas, $\mathrm{X} 1, \mathrm{X} 2, \ldots, \mathrm{XP}$, com $I 1, \ldots, I P$ categorias, respectivamente. Seja $\lambda$ i1i2...iP a probabilidade de determinado indivíduo pertencer ao nível (i1, i2,..., iP), relativamente à variável conjunta $(\mathrm{X} 1, \mathrm{X} 2, \ldots, \mathrm{XP}), \mathrm{com} \mathrm{i} 1=1, \ldots, \mathrm{I} 1, \ldots, \mathrm{iP}=1, \ldots, \mathrm{IP}$. Nestas condições, supondo a existência de uma variável latente $\mathrm{Y}$, com por $\mathrm{S}$ categorias, capaz de explicar as relações entre as variáveis observadas, a probabilidade $\lambda \mathrm{i} 1 \mathrm{i} 2$...iP pode ser definida pelo modelo

$$
\lambda_{i_{1} i_{2} \ldots i_{\mathrm{P}}}=\sum_{s=1}^{S} \lambda_{\mathrm{Y}}(s) \lambda_{\mathrm{X}_{1} \mid \mathrm{Y}=s}\left(i_{1}\right) \lambda_{\mathrm{X}_{2} \mid \mathrm{Y}=s}\left(i_{2}\right) \cdots \lambda_{\mathrm{X}_{\mathrm{P}} \mid Y=s}\left(i_{\mathrm{P}}\right)
$$

onde

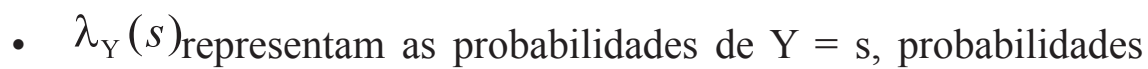
de pertença do indivíduo à classe latente $\mathrm{s}(\mathrm{s}=1, \ldots, \mathrm{S})$, isto é, as probabilidades das classes latentes, também designadas por dimensões relativas ou proporções de mistura, as quais estimam a verosimilhança de que indivíduos pertençam a cada uma das classes.

- $\quad \lambda_{\mathrm{X}_{\mathrm{p}} \mid \mathrm{Y}=\mathrm{s}}\left(i_{\mathrm{p}}\right), \mathrm{p}=1, \ldots, \mathrm{P}$, representa a probabilidade condicional de que a variável Xp esteja na categoria ip, sabendo que a variável latente Y está no nível s.

Na estimação dos modelos de classes latentes, são de fundamental importância na sua estrutura, a estimação das probabilidades das classes latentes ou dimensões relativas e as probabilidades condicionais de certo indivíduo tomar valores em determinadas categorias das variáveis observadas, dado que é membro de uma classe da variável latente. As proporções das classes latentes descrevem a distribuição de probabilidade das classes latentes ou tipologias; tornam-se assim úteis na descrição das prevalências de tipologias dentro da população e na comparação de prevalências entre sub populações. Para uma mais completa descrição sobre a estimação dos modelos de classes latentes, pelo método de máxima vero- 
similhança, através do algoritmo EM (Expectation-Maximization), veja-se McLachlan e Peel (2000) e Fonseca e Cardoso (2007) .

\section{Análise de Dados}

\subsection{Estatística Descritiva}

Considerando por exemplo a variável Current taxes on income, wealth, etc. \% of GDP, é possível verificar (Figura 1) uma grande heterogeneidade entre os países da EU27, nos anos 2000 e 2011, o que por si só pode ser preocupante, tendo em vista o futuro de uma EU que se pretendia coesa. $\mathrm{O}$ mesmo se poderia verificar em relação às restantes variáveis consideradas.

Todavia, o estudo comparativo que será desenvolvido estatisticamente, de forma multivariada, irá realçar essa heterogeneidade, de forma mais precisa e compreensiva.

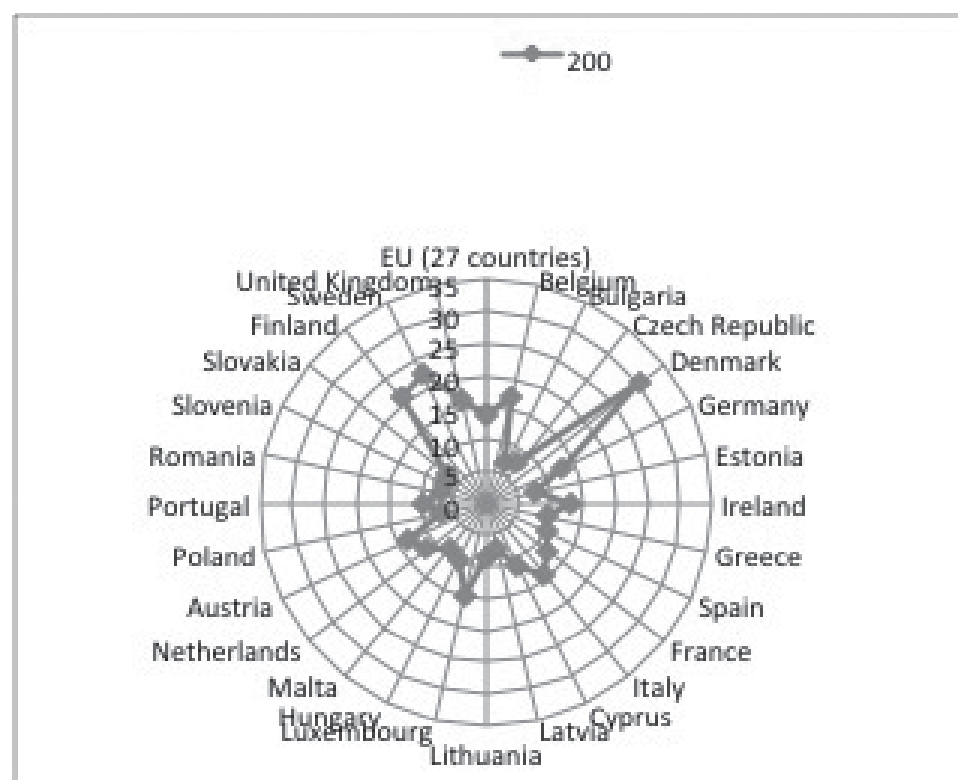




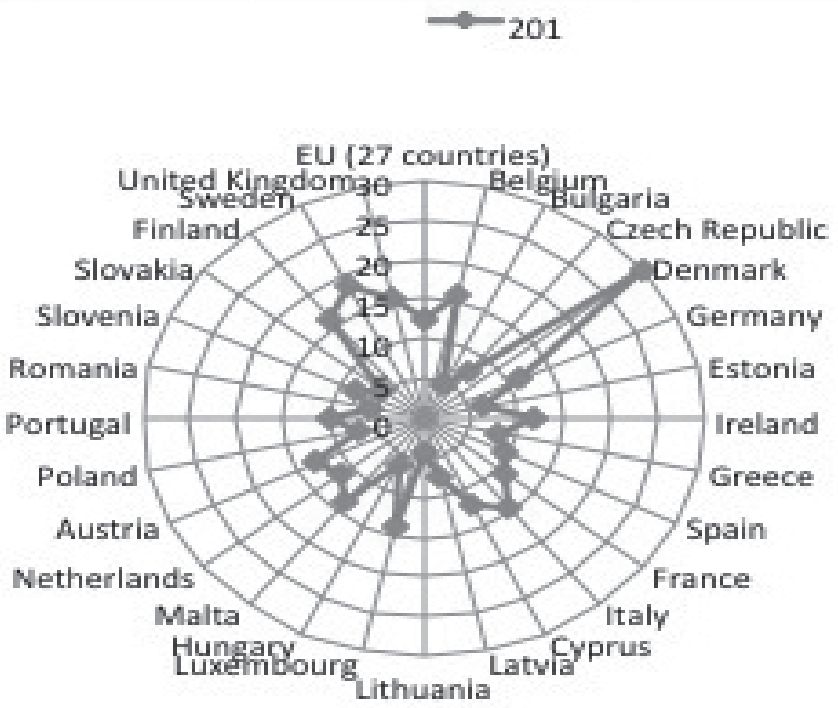

Figura 1: Current taxes on income, wealth, etc. \% of GDP Fonte: Elaborada pelos autores deste artigo

Na Tabela 2 são apresentados os valores das cinco variáveis para os quatro países em maiores dificuldades, Grécia, Irlanda, Portugal e Espanha, mais os casos da Alemanha e Dinamarca e a média EU27. 
Tabela 2: Valores das cinco variáveis nos cinco países considerados

\begin{tabular}{|c|c|c|c|c|c|c|}
\hline & & $\begin{array}{l}\text { Current ta- } \\
\text { xes on inco- } \\
\text { me, wealth, } \\
\text { etc. \% of } \\
\text { GDP }\end{array}$ & $\begin{array}{l}\text { Ratio of ta- } \\
\text { xes and so- } \\
\text { cial security } \\
\text { contributions } \\
\text { on employed } \\
\text { labour income } \\
\text { to total com- } \\
\text { pensation of } \\
\text { employees }\end{array}$ & $\begin{array}{l}\text { Social con- } \\
\text { tributions } \% \\
\text { GDP }\end{array}$ & $\begin{array}{l}\text { Total general } \\
\text { government } \\
\text { expenditure } \\
\% \text { GDP }\end{array}$ & $\begin{array}{l}\text { Total general } \\
\text { government } \\
\text { revenue } \% \\
\text { GDP }\end{array}$ \\
\hline \multirow[t]{7}{*}{2000} & Grécia & 9,7 & 34,5 & 12,5 & 46,7 & 43 \\
\hline & Espanha & 10,3 & 30,5 & 12,9 & 39,2 & 38,2 \\
\hline & Irlanda & 13,2 & 28,5 & 5,6 & 31,2 & 35,9 \\
\hline & Portugal & 9,5 & 22,3 & 10,6 & 41,6 & 38,3 \\
\hline & EU27 & 13,8 & 36,7 & 14 & 44,8 & 45,3 \\
\hline & Alemanha & 12,8 & 39,1 & 18,6 & 45,1 & 46,2 \\
\hline & Dinamarca & 30,3 & 41 & 2,6 & 53,7 & 55,8 \\
\hline \multirow[t]{7}{*}{2011} & Grécia & 8,3 & 31,3 & 12,8 & 50,10 & 40,9 \\
\hline & Espanha & 9,5 & 33 & 13 & 43,6 & 35,1 \\
\hline & Irlanda & 11,7 & 26,1 & 6,6 & 48,7 & 35,7 \\
\hline & Portugal & 9,9 & 23,4 & 12,3 & 48,9 & 44,7 \\
\hline & EU27 & 12,6 & 36 & 13,9 & 49,1 & 44,6 \\
\hline & Alemanha & 11,5 & 37,4 & 16,9 & 45,6 & 44,7 \\
\hline & Dinamarca & 29,9 & 34,8 & 2 & 57,9 & 56 \\
\hline
\end{tabular}

Fonte: Eurostat

É possível assim (1) verificar a evolução entre 2000 e 2011, (2) fazer uma análise comparativa entre países em dificuldades, (3) bem como entre esses países e Alemanha e Dinamarca.

Da análise ressalta uma subida generalizada da despesa, sendo substancial no caso da Irlanda. Em relação às restantes variáveis, verifica-se o seguinte:

1. Grécia: Descida em todas as restantes variáveis;

2. Espanha: Descida da receita;

3. Irlanda: Descida em todas as variáveis, à exceção das contribuições sociais que verificam ligeira subida;

4. Portugal: Subida em todas as variáveis, sendo substancial no que respeita às receitas. 
A Dinamarca salienta-se pelos elevados valores de todas as variáveis, com exceção das contribuições sociais, quase inexistentes.

Preocupante ainda é a constatação de que as receitas e as despesas sendo muito semelhantes, nos países com dificuldades (Grécia, Espanha, Irlanda, Portugal), em 2000, são ainda mais dissemelhantes em 2011, com as despesas a superarem as receitas nos quatro países.

\subsection{Análise Comparativa entre os Países EU27: perfis}

Com o intuito de comparar os países da EU27, de forma multivariada, segundo as variáveis consideradas, poder-se-ia usar a MANOVA caso se verificassem os pressupostos.

Tabela 3: Estimativas dos parâmetros do modelo com duas classes latentes (2000)

\begin{tabular}{|l|l|l|}
\hline & Cluster1 & Cluster2 \\
\hline Overall Probability & 0,5172 & 0,4828 \\
\hline Indicators & & \\
\hline Current taxes on income, wealth, etc. \% of GDP-2000 & & \\
\hline $6,80-7,30$ & $\mathbf{0 , 7 9 8}$ & 0,202 \\
\hline $7,40-9,50$ & $\mathbf{0 , 8 1 7 4}$ & 0,1826 \\
\hline $9,70-11,60$ & 0,4168 & $\mathbf{0 , 5 8 3 2}$ \\
\hline $12-14,90$ & 0,3334 & $\mathbf{0 , 6 6 6 6}$ \\
\hline $16,50-30,30$ & 0,2 & $\mathbf{0 , 8}$ \\
\hline $\begin{array}{l}\text { Ratio of taxes and social security contributions on employed labour } \\
\text { income to total compensation of employees-2000 }\end{array}$ & & \\
\hline $21,60-28,50$ & $\mathbf{1}$ & 0 \\
\hline $29,90-35$ & $\mathbf{0 , 6 8 0 3}$ & 0,3197 \\
\hline $36,30-38,10$ & $\mathbf{0 , 5 9 8 5}$ & 0,4015 \\
\hline $39,10-41,40$ & 0,3175 & $\mathbf{0 , 6 8 2 5}$ \\
\hline $41,80-46,80$ & 0,0002 & $\mathbf{0 , 9 9 9 8}$ \\
\hline Social Contributions \% GDP-2000 & & \\
\hline $2,600-7,600$ & $\mathbf{0 , 8}$ & 0,2 \\
\hline $9,300-11$ & $\mathbf{0 , 9 9 6 4}$ & 0,0036 \\
\hline $11,40-12,90$ & $\mathbf{0 , 5 1 3 2}$ & 0,4868 \\
\hline $13,10-15,10$ & 0,1837 & $\mathbf{0 , 8 1 6 3}$ \\
\hline $16-18,60$ & 0,0008 & $\mathbf{0 , 9 9 9 2}$ \\
\hline Total general government expenditure \% GDP-2000 & & \\
\hline $31,20-37,60$ & $\mathbf{0 , 9 9 9 9}$ & 0,0001 \\
\hline $38,60-41,10$ & $\mathbf{0 , 9 9 9 6}$ & 0,0004 \\
\hline $41,30-45,10$ & $\mathbf{0 , 5 7 7 6}$ & 0,4224 \\
\hline
\end{tabular}




\begin{tabular}{|l|l|l|}
\hline $45,90-49,10$ & 0,0158 & $\mathbf{0 , 9 8 4 2}$ \\
\hline $51,70-55,10$ & 0 & $\mathbf{1}$ \\
\hline Total general government revenue \% GDP-2000 & & \\
\hline $33,90-35,70$ & $\mathbf{0 , 9 9 9 9}$ & 0,0001 \\
\hline $35,90-38,30$ & $\mathbf{0 , 9 8 3 9}$ & 0,0161 \\
\hline $39,90-43$ & 0,4145 & $\mathbf{0 , 5 8 5 5}$ \\
\hline $43,60-49$ & 0,1675 & $\mathbf{0 , 8 3 2 5}$ \\
\hline $50,10-58,70$ & 0 & $\mathbf{1}$ \\
\hline
\end{tabular}

Fonte: Eurostat

Contudo, ainda que se verificassem, pode-se considerar que os modelos de classes latentes constituem uma técnica probabilístico/estatística ideal para classificar casos semelhantes em grupos, de acordo com as características analisadas. Relativamente a essas cinco variáveis, os modelos criaram dois clusters dos 27 países e analisou-se a sua estabilidade, entre 2000 e 2011. Os resultados encontram-se nas Tabelas 3, 4, 5 e 6.

A Tabela 3 mostra as estimativas do modelo selecionado, um modelo com duas classes (clusters) latentes, respetivamente com 52\% e 48\% dos países. Os restantes valores da tabela devem ser interpretados do seguinte modo. Por exemplo, 0,798 e 0,202 representam as probabilidades de que os países apresentem valores da variável Current taxes on income, wealth, etc. \% of GDP-2000 entre 6,80 e 7,30, sabendo que pertencem respetivamente aos clusters 1 e 2 . Assim, porque 0,798 é superior a 0,202 valores da variável entre 6,80 e 7,30 caracterizam o cluster 1 .

Com base neste raciocínio, é possível elaborar o perfil dos 27 países, de acordo com as cinco variáveis analisadas, apresentado na Tabela 4. No cluster 1 encontram-se os países com menores valores em todas as variáveis (Bulgaria, Cyprus, Czech Republic, Estonia, Ireland, Latvia, Lithuania, Luxembourg, Malta, Poland, Portugal, Romania, Spain, United Kingdom), desde impostos até às receitas. Inversamente, o cluster 2 é caracterizado pelos países com maiores valores em todas as variáveis (Austria, Belgium, Denmark, Finland, France, Germany, Greece, Hungary, Italy, Netherlands, Slovakia, Slovenia, Sweden). 
Tabela 4: Perfis dos países EU27 em 2000

\begin{tabular}{|l|l|l|}
\hline Indicators & $\begin{array}{l}\text { Cluster 1 } \\
\text { Bulgaria, Cyprus, Cze- } \\
\text { ch Republic, Estonia, } \\
\text { Ireland, Latvia, Lithua- } \\
\text { nia, Luxembourg, Mal- } \\
\text { ta, Poland, Portugal, } \\
\text { Romania, Spain, United } \\
\text { Kingdom }\end{array}$ & $\begin{array}{l}\text { Austria, Belgium, Den- } \\
\text { Gark, Finland, France, } \\
\text { germany, Greece, Hun- } \\
\text { Slovakia, Setherlands, } \\
\text { Sweden }\end{array}$ \\
\hline $\begin{array}{l}\text { Current taxes on income, wealth, etc. \% } \\
\text { of GDP-2000 }\end{array}$ & Até 9,5 & Mais de 9,7 \\
\hline $\begin{array}{l}\text { Ratio of taxes and social security contri- } \\
\text { butions on employed labour income to to- } \\
\text { tal compensation of employees-2000 }\end{array}$ & Até 38,10 & Mais de 39,10 \\
\hline Social contributions \% GDP-2000 & Até 12,90 & Mais de 13,10 \\
\hline $\begin{array}{l}\text { Total general government expenditure \% } \\
\text { GDP-2000 }\end{array}$ & Até 45,10 & Mais de 45,90 \\
\hline $\begin{array}{l}\text { Total general government revenue \% } \\
\text { GDP-2000 }\end{array}$ & Até 38,30 & Mais de 39,90 \\
\hline
\end{tabular}

Fonte: Elaborada pelos autores deste artigo

Ao fim de 11 anos, houve alterações significativas nos países EU27, segundo as cinco variáveis consideradas? Para responder a esta questão usa-se novamente os modelos de classes latentes para traçar o perfil dos países segundo as mesmas variáveis. As estimativas dos parâmetros do modelo selecionado encontram-se na Tabela 5, as quais permitirão o traçado do perfil.

Tabela 5: Estimativas dos parâmetros do modelo com 2 classes latentes (2011)

\begin{tabular}{|l|l|l|}
\hline & Cluster1 & Cluster2 \\
\hline Overall Probability & $\mathbf{0 , 5 9 1 9}$ & $\mathbf{0 , 4 0 8 1}$ \\
\hline Indicators & & \\
\hline Current taxes on income, wealth, etc. \% of GDP-2011 & & \\
\hline $\mathbf{4 , 4 0 0}-6,400$ & $\mathbf{0 , 8}$ & $\mathbf{0 , 2}$ \\
\hline $\mathbf{6 , 6 0 0}-8,300$ & $\mathbf{0 , 8 3 6 1}$ & $\mathbf{0 , 1 6 3 9}$ \\
\hline $\mathbf{9 , 5 0 0}-11,50$ & $\mathbf{0 , 4 1 0 7}$ & $\mathbf{0 , 5 8 9 3}$ \\
\hline $\mathbf{1 1 , 7 0}-14,30$ & $\mathbf{0 , 6 6 6 8}$ & $\mathbf{0 , 3 3 3 2}$ \\
\hline $\mathbf{1 5 , 7 0}-29,90$ & $\mathbf{0 , 2}$ & $\mathbf{0 , 8}$ \\
\hline $\begin{array}{l}\text { Ratio of taxes and social security contributions on employed labour } \\
\text { income to total compensation of employees-2011 }\end{array}$ & & \\
\hline $\mathbf{2 1 , 7 0}-26,10$ & $\mathbf{1}$ & $\mathbf{0}$ \\
\hline $\mathbf{2 7}-31,70$ & $\mathbf{0 , 9 9 9 1}$ & $\mathbf{0 , 0 0 0 9}$ \\
\hline
\end{tabular}




\begin{tabular}{|l|l|l|}
\hline $\mathbf{3 2}-35$ & $\mathbf{0 , 6 8 1}$ & $\mathbf{0 , 3 1 9}$ \\
\hline $\mathbf{3 6 , 9 0}-39,30$ & $\mathbf{0 , 3 3 0 3}$ & $\mathbf{0 , 6 6 9 7}$ \\
\hline $\mathbf{3 9 , 4 0}-42,60$ & $\mathbf{0 , 0 0 0 2}$ & $\mathbf{0 , 9 9 9 8}$ \\
\hline Social contributions \% GDP-2011 & & \\
\hline $\mathbf{2}-7,600$ & $\mathbf{0 , 5 9 8 6}$ & $\mathbf{0 , 4 0 1 4}$ \\
\hline $\mathbf{8 , 5 0 0}-11,40$ & $\mathbf{1}$ & $\mathbf{0}$ \\
\hline $\mathbf{1 1 , 9 0}-12,50$ & $\mathbf{0 , 7 9 9 9}$ & $\mathbf{0 , 2 0 0 1}$ \\
\hline $\mathbf{1 2 , 8 0}-15,50$ & $\mathbf{0 , 4 3 0 4}$ & $\mathbf{0 , 5 6 9 6}$ \\
\hline $\mathbf{1 6 , 2 0}-18,80$ & $\mathbf{0 , 0 1 1}$ & $\mathbf{0 , 9 8 9}$ \\
\hline Total general government expenditure \% GDP-2011 & & \\
\hline $\mathbf{3 5 , 2 0}-38,20$ & $\mathbf{1}$ & $\mathbf{0}$ \\
\hline $\mathbf{3 9 , 1 0}-43,60$ & $\mathbf{0 , 9 8 9 1}$ & $\mathbf{0 , 0 1 0 9}$ \\
\hline $\mathbf{4 5 , 6 0}-48,90$ & $\mathbf{0 , 6 0 7 4}$ & $\mathbf{0 , 3 9 2 6}$ \\
\hline $\mathbf{4 9}-50,90$ & $\mathbf{0 , 3 4 7 5}$ & $\mathbf{0 , 6 5 2 5}$ \\
\hline $\mathbf{5 1 , 3 0}-57,90$ & $\mathbf{0}$ & $\mathbf{1}$ \\
\hline Total general government revenue \% GDP-2011 & & \\
\hline $\mathbf{3 2}-35,10$ & $\mathbf{1}$ & $\mathbf{0}$ \\
\hline $\mathbf{3 5 , 6 0}-40,30$ & $\mathbf{0 , 9 8 9 1}$ & $\mathbf{0 , 0 1 0 9}$ \\
\hline $\mathbf{4 0 , 8 0}-44,50$ & $\mathbf{0 , 8 1 6 3}$ & $\mathbf{0 , 1 8 3 7}$ \\
\hline $\mathbf{4 4 , 7 0}-49,50$ & $\mathbf{0 , 1 7 4 6}$ & $\mathbf{0 , 8 2 5 4}$ \\
\hline $\mathbf{5 0 , 7 0}-56$ & $\mathbf{0}$ & $\mathbf{1}$ \\
\hline
\end{tabular}

Fonte: Elaborada pelos autores deste artigo

Volvidos onze anos, considerando as mesmas variáveis, pode concluir-se que os perfis se mantiveram muito estáveis.

A Tabela 5 mostra as estimativas do modelo selecionado e no que respeita ao número de clusters verifica-se igualmente uma situação de estabilidade, pois tal como em 2000, também em 2011 se verificam dois clusters.

Contudo, verifica-se a saída da Grécia e da Eslováquia do cluster 2 para o cluster 1, conforme Tabela 64. Quanto à Grécia, esta evolução é compreensível em face do manifesto agravamento da sua situação financeira e orçamental. 
Tabela 6: Perfis dos países EU27 em 2011

\begin{tabular}{|l|l|l|}
\hline & $\begin{array}{l}\text { Cluster 1 } \\
\text { Bulgaria, Cyprus, } \\
\text { Czech Republic, Es- } \\
\text { tonia, Greece, Ireland, } \\
\text { Latvia, Lithuania, Lux- } \\
\text { embourg, Malta, Poland, } \\
\text { Portugal, Romania, } \\
\text { Slovakia, Spain, United } \\
\text { Austria, Belgium, Den- } \\
\text { Kark, Finland, France, } \\
\text { Germany, Hungary, Ita- } \\
\text { ly, Netherlands, Slove- } \\
\text { nia, Sweden }\end{array}$ \\
\hline $\begin{array}{l}\text { Current taxes on income, wealth, etc. \% } \\
\text { of GDP-2011 }\end{array}$ & Até 8,3;11,70-14,30 & $\begin{array}{l}\mathbf{9 , 5 0 0}-11,50 ; \text { Mais de } \\
29,90\end{array}$ \\
\hline $\begin{array}{l}\text { Ratio of taxes and social security contri- } \\
\text { butions on employed labour income to } \\
\text { total compensation of employees-2011 }\end{array}$ & Até 35 & Mais de 36,90 \\
\hline Social contributions \% GDP-2011 & Até 12,50 & Mais de 12,80 \\
\hline $\begin{array}{l}\text { Total general government expenditure \% } \\
\text { GDP-2011 }\end{array}$ & Até 45,60 & Mais de 49 \\
\hline $\begin{array}{l}\text { Total general government revenue \% } \\
\text { GDP-2011 }\end{array}$ & Até 44,50 & Mais de 44,70 \\
\hline
\end{tabular}

Fonte: Elaborada pelos autores deste artigo

Em resposta às questões colocadas verifica-se que os instrumentos legais e políticos existentes não foram suficientes para disciplinar o comportamento dos Estados-Membros. Estes continuaram a desenvolver as suas políticas financeiras e orçamentais públicas tendo primacialmente em conta os respetivos interesses nacionais. Não houve, portanto, uma evolução qualitativa, mas, antes, um agravamento, tornado mais evidente com a crise financeira que, entretanto, sobreveio.

Também não se pode afirmar que esses Estados hajam desenvolvido trajetórias de ajustamento rumo à União Económica e Monetária e no contexto da própria UEM. Os clusters supra evidenciam uma fraca evolução do posicionamento dos Estados-Membros.

As finanças públicas europeias continuam a revelar um problema de disciplina orçamental, impondo-se a necessidade de uma margem acrescida de prudência na condução das políticas orçamental e de supervisão do sistema financeiro europeu. O sector público tem revelado, na generalidade dos Estados-Membros um grave problema de disciplina orçamental, o 
que tem fragilizado a confiança dos agentes económicos no desempenho das contas públicas.

Esta análise comparativa explica por que falharam os mecanismos de disciplina financeira que deveriam suportar o funcionamento da moeda única. A estabilidade dos clusters (dois em 2000 e dois em 2011) verificada, bem como a quase estabilidade interna de cada cluster (apenas dois países trocaram o cluster 2 pelo 1) mostra que a heterogeneidade dos países verificada em 2000 continua a verificar-se em 2011.

\section{Conclusões}

Como se vê, a variável relativa aos impostos correntes sobre o rendimento, património observa um comportamento bastante homogéneo ao longo do período considerado. Observa-se uma tendência no sentido de eliminar ou reduzir os escalões mais elevados do imposto de renda das pessoas físicas, fenómeno que está, de resto, em linha com o que se verificou com alguns dos Estados da OCDE (exceção feita para o Luxemburgo que mantém um número de escalões do imposto de renda acima dos 10, para Portugal que criou em 2003 um escalão de 42\% e em 2010 de $45 \%$ e para a Dinamarca que subiu a tributação geral dos rendimentos sujeitos a imposto de renda).

A variável relativa aos impostos e contribuições para segurança social sobre os rendimentos do trabalho assalariado a remuneração total dos trabalhadores apresenta uma evolução heterogénea, sendo claro o seu sentido de agravamento num bom número de países. Isso significa um agravamento da carga fiscal geral e, consequentemente, um crescimento da taxa de esforço fiscal.

As Contribuições sociais apresentam, no decénio sob consideração, um idêntico sentido de agravamento pontual ou de manutenção do seu peso relativo em percentagem do PIB. No mesmo sentido evoluiu a despesa geral dos Estados-membros em percentagem do PIB. A maioria dos Estados viu agravado o valor da despesa em percentagem do PIB, tais como a Franca, Grécia, Bélgica, Dinamarca, Holanda, etc. Apenas uns poucos Estados, tais como a Eslováquia e a Áustria, mantiveram cons- 
tante a despesa total ao passo que num número considerável se observa a manutenção ou um ligeiro aumento dos níveis de despesa.

A receita total do Estado em percentagem do PIB apresenta uma evolução positiva. Ela cresceu na generalidade dos países da UE, como é o caso do Reino Unido, Portugal, Hungria, Eslováquia ou Luxemburgo. Como se denota, o agravamento da carga fiscal geral ficou a dever-se à necessidade de financiar as despesas crescentes pelo que se pode afirmar que não houve uma verdadeira consolidação geral das contas públicas, mas uma generalizada indisciplina financeira. Os défices crescentes foram alimentados por receitas (de impostos) crescentes.

No caso de Portugal a despesa do Estado foi agravada com o recurso numa escala invulgar a parcerias público-privadas e com um Setor Empresarial do Estado (SEE) muito indisciplinado e desestruturado. Estes compromissos assumidos aumentam a pressão sobre as contas públicas no médio prazo. Para além deste risco orçamental, verificou-se também um efeito de crowding-out do sector privado: o elevado nível de endividamento do SEE, designadamente junto dos bancos, absorveu uma fração considerável do crédito que, desta forma, não pôde ser destinado ao sector privado, com destaque para as pequenas e médias empresas (PMEs) e as empresas exportadoras.

Os dados demonstram que não a generalidades dos Estados europeus não realizou um efetivo saneamento das suas contas públicas nem encetou planos de reforma do Estado e das Administrações públicas. Isto é, pese embora as metas definidas, a existência de etapas programadas para a introdução do euro e, depois disso, a existência de limites para o défice das contas públicas e o endividamento público, nem os 27 Estados europeus nem os Estados da zona euro encetarem em devido tempo verdadeiros programas de saneamento e de consolidação orçamental a médio e longo prazo.

A estrutura das variáveis assinaladas demonstra, antes, uma evolução na continuidade nos gastos públicos dos Estados da zona euro como se os limites impostos pela moeda única não existissem. Na prática, eles evidenciam um desinteresse real pelo aprofundamento do projeto do euro como moeda da União europeia e universal. 


\section{Referências}

AMADOR, João; CUNHA, Jorge Correia da. Regras orçamentais na UE: algumas linhas de orientação para a sua reforma. Boletim Económico do Banco de Portugal, dezembro de 2004. Disponível em: $<$ http://docentes.fe.unl.pt/ jamador/Textos/BE_PEC.pdf $>$. Acesso em: 22 ago. 2012.

CATARINO, João Ricardo; TAVARES F. F. José (Org.). Finanças públicas da União Europeia. Coimbra: Almedina, 2012a.

CATARINO, João Ricardo. Finanças públicas e direito financeiro. Coimbra: Almedina, 2012b.

CATARINO, João Ricardo. Quality and sustainability in public finance: the European case. Journal Global Business \& Economics Anthology, USA, 2011.

CHEVAUCHEZ, Benoit. Les effets de la construction européenne sur notre système de finances publiques. RFPP - Revue Française de Finances Publiques, n. 68, Paris, 1999.

CLOGG, Clifford C. Latent class models. In: G. ARMINGER, C. C. Clogg; SOBEL, M. E. (Ed.) Handbook of Statistical Modeling for the Social and Behavioral Sciences, p. 311-359, 1995. (New York: Plenum) ESCLASSAN, Marie-Christine. Les effets de la construction européenne sur le pouvoir budgétaire des États membres: le cas de la France. RFPP Revue Française de Finances Publiques, Paris, n. 68, 1999.

FERREIRA, Eduardo Paz. Da dívida pública e das garantias dos credores do estado. Coimbra: Almedina, 1995.

FONSECA, Jaime R. S. Clustering in the field of social sciences: that's your choice. International Journal of Social Research Methodology. Routledge: Taylor \& Francis Group, 2012,

FONSECA, Jaime R. S.; CARDOSO, Margarida G. M. S. MixtureModel Cluster Analysis using Information Theoretical Criteria. Intelligent Data Analysis, v. 11, n. 2, p. 155-173, IOS Press, 2007. 
FRANCO, Sousa. Finanças Europeias. Coimbra: Almedina,1990. v. I. FRANCO, Sousa et al. Finanças Europeias: introdução e orçamento. Coimbra: Almedina, 1994.

LAZARSFELD, Paul F.; HENRY, N. W. Latent Structure Analysis. Boston: Houghton Mifflin, 1968.

LLAU, Pierre. Les contractions budgétaires en Europe. RFPP - Revue Française de Finances Publiques, Paris, n. 68,1999.

MARSDEN, Peter V. Latent structure models for relationally defined social classes, The American Journal of Sociology, v. 90, p. 1.002$1.021,1985$.

McLACHLAN, G. F.; PEEL, David. Finite Mixture Models. New York: John Wiley \& Sons, Inc., 2000.

ORSONI, Gilbert. Les pratiques de régulation budgétaire, na RFFP, com o tema, L'Union européenne et les finances publiques nationales. RFPP Revue Française de Finances Publiques, Paris, n. 68, 1999.

TAVARES, José F. F. Estudos de administração e finanças públicas. Coimbra: Almedina, 2004.

REGULAMENTO (CE) n. 1.055/2005 do Conselho de 27 de junho de 2005 (altera o Regulamento (CE) n. 1.466/97 relativo ao reforço da supervisão das situações orçamentais e à supervisão e coordenação das políticas económicas foi publicado no JO L 174/4, em 7 de julho de 2005) e Anexo II - Melhorar a aplicação do pacto de estabilidade e crescimento. [2005]. Disponível em: <http://www.fd.uc.pt/CI/CEE/pm/ LegCE/Pacto-Relatorio_Conselho-23-3-2005.htm>. Acesso em: 22 ago. 2012.

REGULAMENTO (CE) n. 1.446/97 do Conselho, de 7 de julho de 1997, relativo ao reforço da supervisão das situações orçamentais e à supervisão e coordenação das políticas económicas. [1997].

REGULAMENTO (CE) n. 1.466/97, do Conselho, de 7 de julho, relativo ao esforço de supervisão das situações orçamentais e à supervisão e coordenação das políticas económicas, com as alterações introduzidas pelo Regulamento (CE) n. 1.055/2005. 
REGULAMENTO (CE) n. 1.467/97, do Conselho, de 7 de julho, que constituem as bases do PEC - Pacto de Estabilidade e Crescimento. [1997].

REGULAMENTO (CE) n. 1.467/97, do Conselho, de 7 de julho, que constituem as bases do PEC - Pacto de Estabilidade e Crescimento. [1997].

REGULAMENTO (CE) n. 3.605/93 do Conselho, de 22.11.1993, relativo à aplicação do protocolo sobre o procedimento relativo aos défices excessivos anexo ao Tratado que institui a Comunidade Europeia, Jornal Oficial n. L 332 de 31/12/1993 p. 0007-0009. [1993].

REGULAMENTO n. 1.467/97, do Conselho, de 7 de julho de 1997, publicado no Jornal Oficial L n. 209 de 2/08/1997 foi alterado pelo 1.056/2005 de 7. 7. 2005 - JO, L, 174/5. [1997].

RESOLUÇÃO do Conselho Europeu de Amesterdão, de 17 de julho de 1997, o Regulamento (CE) n. 1.466/97, do Conselho, de 7 de julho, e Regulamento (CE) n. 1.467/97, do Conselho, de 7 de julho, que constituem as bases do PEC - Pacto de Estabilidade e Crescimento.

RESOLUÇÃO do Conselho Europeu de Amesterdão, de 17 de julho de 1997.

RESOLUÇÃO do Conselho Europeu sobre o Pacto de Estabilidade e Crescimento, Amesterdão, 17 de junho de 1997, (97/C 236/01), JO n. C 236 de 02/08/1997.

João Ricardo Catarino é Professor universitário e pesquisador do Centro de Administração e Políticas Públicas (CAPP) e do Instituto Superior de Ciências Sociais e Políticas (ISCSP) da Universidade Técnica de Lisboa (UTL). E-mail: jcatarino@iscso.utl.pt.

Endereço profissional: Universidade Técnica de Lisboa Instituto Superior de Ciências Sociais e Políticas - Centro de Administração e Políticas Públicas. Rua Almerindo Lessa Lisboa, 1600-100, Lisboa, Portugal. 
Jaime Fonseca é Professor universitário e pesquisador do Centro de Administração e Políticas Públicas (CAPP) e do Instituto Superior de Ciências Sociais e Políticas (ISCSP) da Universidade Técnica de Lisboa (UTL). E-mail: jaimefonseca@iscsp.utl.pt

Endereço profissional: Universidade Técnica de Lisboa Instituto Superior de Ciências Sociais e Políticas - Centro de Administração e Políticas Públicas. Rua Almerindo Lessa Lisboa, 1600-100, Lisboa, Portugal. 